\title{
José Ingenieros y Juan Creaghe: las polémicas entre el socialismo revolucionario y el anarquismo en el periódico La Montaña
}

\author{
José Ingenieros and Juan Creaghe: polemics between revolutionary \\ socialism and anarchism in the newspaper La Montaña
}

Pilar Parot Varela*

\begin{abstract}
Resumen
El artículo analiza la controversia suscitada en el periódico La Montaña entre el anarquista Juan Creaghe y el socialista José Ingenieros, enfatizando las transformaciones ideológicas que cada uno de los interlocutores experimentaba, a fin de mostrar el modo en que sus respectivas posiciones se redefinen y se consolidan.
\end{abstract}

Palabras clave: Socialismo - Anarquismo - Periódico La MontañaRevolución- Libertad- Moral.

\begin{abstract}
The article analyzes the controversy in the newspaper La Montaña, between the anarchist Juan Creaghe and socialist José Ingenieros, emphasizing the ideological transformations that each of the partners felt, to show how their positions are redefined and consolidated.
\end{abstract}

Keywords: Socialism - Anarchism - Newspaper La Montaña - RevolutionFreedom- Moral.

\section{Introducción}

El vínculo entre el joven estudiante de medicina José Ingenieros y el médico anarquista Juan Creaghe se desenvuelve en un contexto político signado por la reciente formación del Partido socialista en Argentina y por la presencia de un significativo proceso de transformación en el seno del movimiento anarquista.

En 1897 comienza a publicarse La Montaña. Periódico socialista revolucionario, editado por Ingenieros y el poeta cordobés Leopoldo Lugones. Esta publicación surge como espacio de expresión de la tendencia revolucionaria encabezada por estos jóvenes al interior del Partido Socialista, la cual se opuso radicalmente al reformismo del líder Juan B. Justo. A pesar de la corta edad de sus integrantes y de la breve experiencia política con la que contaban, la corriente izquierdista había logrado imponer, en el Congreso Constituyente del Partido en 1896, una serie de

\footnotetext{
* Argentina, Licenciada en Filosofía. Doctoranda en Filosofía por la Universidad de Buenos Aires. Integrante del proyecto UBACYT 01/C091, de la Facultad de Filosofía y Letras. E-mail pilarparotv@gmail.com.
} 
modificaciones a la "Declaración de Principios" redactada por Justo. Por otro lado, a fines de 1897 se consolidaba al interior del anarquismo una tendencia que dejaba en el pasado las reivindicaciones insurreccionales del individualismo, y comenzaba a adoptar ciertas formas de organización e intervención en el movimiento obrero. En el marco de una lucha ideológica por alcanzar la hegemonía dentro de la clase obrera, anarquistas y socialistas comenzaron a participar simultáneamente en diferentes manifestaciones e, incluso, reuniones de discusión, que a menudo eran publicadas en la prensa anarquista y socialista de esos años.

El carácter general del periódico La montaña, enfáticamente anti-estatista, antiautoritario y atravesado por un tono moral en su crítica hacia el capitalismo, hizo que en ocasiones se lo ligara a la ideología anárquica. Es así que algunos autores analizaron el grado de influencia del anarquismo tanto en La Montaña como en el pensamiento de juventud de Ingenieros. En La Montaña. Jacobinismo y Orografía, Marcela Croce señala que el periódico La Montaña se funde dentro del universo anarquista. Oscar Terán, en José Ingenieros: pensar la Nación, ha inscripto la primera etapa del pensamiento de Ingenieros (1895-1898) dentro de la ideología social-anarquista debido a la adopción de ciertas ideas y valores propios del anarquismo. Si bien los factores libertarios efectivamente estuvieron presentes en la obra de Ingenieros, no podemos pasar por alto las apreciaciones de Horacio Tarcus en Marx en Argentina. Allí el autor advierte que muchas ideas anarquistas formaban parte del imaginario ideológico de izquierda y también fueron retomadas por los socialistas. En este sentido, no resulta extraño que estos matices se entremezclaran en la concepción socialista de Ingenieros y en el periódico La Montaña el cual, por otra parte, se autodefinió desde el inicio como "socialista revolucionario".

El tono libertario de La Montaña y la coexistencia entre socialistas y anarquistas en el movimiento obrero posibilitaron que este periódico fuese tribuna para el intercambio de posiciones entre Ingenieros y Creaghe. Una nota publicada por la redacción del periódico proponía un acercamiento progresivo del anarquismo proorganizador hacia el socialismo, lo cual provocó la inmediata respuesta de Creaghe, desencadenando así una larga polémica. En 1897 el anarquista dejaba de editar El Oprimido, periódico en el cual había empezado a esbozar una posición moderada, para luego apoyar ideológica y económicamente la creación de La Protesta Humana, periódico que influyó notablemente en el afianzamiento de la tendencia organizadora del anarquismo.

El objetivo de este trabajo es reconstruir y contextualizar la polémica entre Ingenieros y Creaghe, a fin de mostrar que la misma se ve atravesada por las tensiones que cada uno de los interlocutores vivía en relación a otras tendencias dentro de su propia posición ideológica. Ingenieros definía su propuesta revolucionaria en tensión con el socialismo reformista de Justo y, a través de la posibilidad de convertir a los anarquistas a su tendencia. Creaghe caminaba hacia la consolidación de la línea organizadora a partir de una oposición al sector individualista del anarquismo, y a través de la interpelación de algunos socialistas que irrumpían en el interior mismo del anarquismo.

Como resultado del debate, ambos contrincantes consolidarán posiciones, en gran medida, diferentes a las defendidas inicialmente. El progresivo viraje de Creaghe hacia una perspectiva más moderada del anarquismo culminó en la adopción de modos de organización para la lucha y para la vida en sociedad, aunque no fue 
suficiente para encontrar en el socialismo el punto de llegada, tal como lo pretendía Ingenieros. Asimismo, la postura del joven socialista, inicialmente revolucionaria, irá acercándose gradualmente al reformismo que antes rechazaba y encontrará más contrapuntos que afinidades en relación al anarquismo.

Las diferencias consolidadas en el transcurso de la polémica nos conducen a concluir, además, que los rasgos libertarios que inicialmente presenta la posición socialista de Ingenieros no parecen haber sido retomados a partir de la teoría anarquista. En primer lugar porque la misma propuesta de Ingenieros por alentar una conversión del anarquismo en el socialismo ya implica un intención por reafirmar su postura socialista. En segundo lugar porque muchos elementos característicos de las teorías anarquistas que Ingenieros adopta estaban también presentes en otras corrientes de pensamiento y en otros autores socialistas a los que con frecuencia Ingenieros alude y que gozaban de una fuerte presencia en La Montaña.

Para desarrollar el trabajo realizaremos una división en apartados en base a los principales ejes conceptuales que creemos que organizan la polémica y reflejan el trasfondo teórico en el que ella se desenvuelve. En el primer apartado, a modo introductorio, haremos un recorrido por las trayectorias políticas y los perfiles ideológicos de ambos interlocutores, haciendo hincapié en las condiciones sociopolíticas que hicieron posible ese encuentro. En el segundo apartado analizaremos la discusión respecto de los métodos de acción, a partir de la definición del concepto de revolución. En la tercera parte, estudiaremos la polémica a propósito de las lógicas que presidieron tanto al ideario anarquista como al socialista; para ello analizaremos el concepto de libertad tal como fue definido por Ingenieros y por Creaghe, y el modo en que esta definición marcó una diferencia en relación a los fines que cada uno de ellos persiguió. En el cuarto y último apartado, realizaremos un análisis acerca de la presencia de ciertas connotaciones de tipo moral en las concepciones del anarquismo y en el socialismo de Ingenieros en el contexto de una polémica sobre la moral anarquista que adquirió gran repercusión entre los libertarios.

\section{Las trayectorias de Ingenieros y Creaghe}

Los primeros pasos en la actividad política de Ingenieros transcurrieron en sus años de estudiante en la Facultad de Medicina, durante los cuales el socialista comienza a participar de las primeras manifestaciones ${ }^{1}$ y entabla relaciones con Justo, quien por ese entonces era su profesor. Hacia 1894 se realizaba la fundación del Centro Socialista Universitario ${ }^{2}$, del cual Ingenieros, con sólo 18 años de edad, sería su primer secretario; asimismo Justo se incorporaba a la Agrupación Socialista ${ }^{3}$ desde

\footnotetext{
${ }^{1}$ El proyecto presentado por el concejal Eduardo Pittaluga a fin de establecer la jornada de 8 hs para los empleados municipales convocó una manifestación el 13 de octubre de 1894 a la que asistieron Ingenieros y Ángel Giménez. Fue allí donde los jóvenes entablaron un vínculo político con Justo, quien también había colaborado con el proyecto.

${ }^{2}$ Fundado el 7 de diciembre, la comisión inicial quedó conformada por José Ingenieros como secretario y Ángel Giménez, A. Ferrari, Rafael Rodríguez, Domingo Guglialmelli y Bartolomé Firpo como vocales. En 1896 se agregaron Emilio Onrubia, A. Ferrané y Justo como vocales. Guglialmelli pasó a ser secretario de actas.

${ }^{3}$ La Agrupación socialista se constituyó en 1892, luego de la disolución de la Federación Obrera, a fin de sentar las bases para la creación de un partido obrero, a través del periódico El Socialista. La Federación Obrera fue una organización intersindical conformada en 1890, que además estaba ligada a
} 
donde proyecta la edición del periódico La Vanguardia, órgano de dicha agrupación, a fin de delinear el programa para la creación de un Partido. En 1895 Lugones viaja desde Córdoba hacia Buenos Aires para vincularse con los grupos socialistas y allí inicia su estrecha amistad con Ingenieros. Al año siguiente se instala definitivamente en el barrio de Barracas, integrándose al Centro Socialista Barracas al Norte. Sin embargo, no sólo el socialismo unirá a estos jóvenes sino también su participación en el ala modernista del Ateneo de Buenos Aires, en torno al cual el poeta Rubén Darío constituyó el cenáculo conocido como La Syringa. El pasaje por esta asociación artística y literaria será el origen de los motivos modernistas que luego aparecerán en La Montaña.

En el clima previo a la configuración del Partido Socialista, Ingenieros publica su folleto "¿Qué es el socialismo?" (1895), editado por la Biblioteca del Centro Socialista Universitario. Allí, el joven socialista se define como representante y difusor de la doctrina del "socialismo científico", esto es, de aquello que ella "propone como solución a esa desigualdad de condiciones que surge como lógica consecuencia de una errónea organización económica (...)” (1895:108). En esta primera publicación ya podemos encontrar, esbozados, tres factores que marcarán la obra de juventud del socialista. En primer lugar, la influencia del evolucionismo de Spencer que lleva a Ingenieros sostener una concepción determinista sobre el desarrollo de la sociedad, según la cual ésta evoluciona obedeciendo a determinadas relaciones de causalidad. Este evolucionismo mecanicista, a su vez, fundamenta el determinismo económico que Ingenieros recoge de las teorías de Aquiles Loria ${ }^{4}$ y de Enrique Ferri, a partir de las cuales interpreta la cuestión social en términos económicos. En particular, Ingenieros adopta del italiano Ferri una lectura positiva del marxismo ${ }^{5}$ que considera al factor económico determinado por el ambiente natural y, a su vez, determinante de los fenómenos políticos, sociales y religiosos. Sobre esta idea Ingenieros fundamenta la verdad de la explicación científica acerca de la sociedad la cual, según él, anuncia el advenimiento del sistema de producción socialista:

Quiere demostrar (el folleto) que el socialismo, más que una organización social impuesta, es una consecuencia lógica y necesaria de la evolución económica que se ha iniciado, y que por la fuerza de los hechos debe implantarse como regulador de las producciones y consumos, y como nivelador de las condiciones individuales ante los medios de producción (1895:108).

En tercer lugar, podemos observar su explícito repudio frente a la concepción insurreccional de los anarquistas, a través de la cual éstos pretenden un cambio radical: "Platónico es suponer que un cambio radical en las instituciones pueda realizarse por una rebelión localizada, por un movimiento prematuro o por un golpe

la Internacional socialista. Esta federación, cuyos intereses fueron expresados mediante el periódico $\mathrm{El}$ Obrero, comprendía no sólo a los socialistas sino también a los anarquistas y a organizaciones de connotación mazzinista. En 1893 ambos periódicos dejaron de editarse y la Agrupación socialista convocó a una reunión para editar un nuevo periódico: La Vanguardia. Con el impulso de Justo, la Agrupación socialista pasó a llamarse Centro Socialista Obrero.

${ }^{4}$ Ingenieros adoptó de Loria la interpretación del fenómeno social en términos de una desigualdad de hecho que choca con una igualdad de derecho, lo cual establece un abismo infranqueable entre el proletario y el productor y este es el origen del problema económico. En "El arte de la sociedad futura" de 1895 Ingenieros citaba la frase de Loria "iguales en derecho, el proletario que muere de hambre y el archimillonario están separados por un abismo".

${ }^{5}$ Sobre la influencia del marxismo en la obra temprana de Ingenieros véase Falcón (2008). 
de Estado" (Ingenieros, 1895:49). Esto, según el joven socialista, resulta de la falta de rigor científico con la que el anarquismo produce sus teorías sobre la nueva sociedad y los modos de alcanzar la misma.

El primer vínculo de Ingenieros con los anarquistas tuvo su origen en las luchas obreras producidas en Argentina durante los años 1896 y 1897. Ellas configuraron un escenario para la intervención simultánea de socialistas y anarquistas, cada cual nucleado en diferentes colectivos obreros. El aumento en la desocupación y la baja calidad de las condiciones laborales habían provocado una gran cantidad de manifestaciones que confluyeron en la gran huelga de los ferrocarrileros, a la cual Ingenieros prestó su apoyo desde el Centro Socialista Revolucionario de Barracas ${ }^{6}$. En un artículo periodístico titulado "La huelga de los ferrocarrileros y mecánicos. Junín, Tolosa, Brown y Caballito", de1896, Ingenieros sostiene: "la huelga general es un hermoso ideal", aunque señala que no debe realizarse bajo el sistema burgués. Asimismo, señala "el día en que los trabajadores de todos los países declarasen huelga general, no habrá sistema que derribar y se vivirá en una sociedad sin autoridad, ni salario ni propiedad" (Ingenieros, 1896:18). Para Ingenieros la huelga aspiraba a una transformación total y no al logro de mejoras parciales, por ello resultaba una herramienta complementaria para la lucha política, cuya finalidad radicaba en la difusión del socialismo revolucionario.

La situación de los trabajadores condujo a los anarquistas a contemplar la posibilidad de intervenir en las luchas obreras y sindicatos, cuestión que ya venía provocando grandes polémicas dentro del anarquismo, marcando una escisión, todavía inminente, entre quienes se negaban a participar en tales sucesos y quienes creían necesario adoptar ciertas formas de organización. Como señala Gonzalo Zaragoza Ruvira, desde mediados de la década de los '90 la presencia de grupos anarquistas partidarios de la organización irá aumentando progresivamente en gran parte como consecuencia del fortalecimiento de esta tendencia en España e Italia. Estos grupos buscaban una alternativa frente a la tendencia que, desde 1888 venía apoyando la libre iniciativa y la propaganda escrita, principalmente mediante el periódico El Perseguido. A partir 1894 surgen una serie de periódicos de tendencia anarquista moderada que reaccionaban frente a las exageraciones terroristas de la corriente individualista: La Questione Sociale (1894-96), La Voz de la Mujer (18961897), El Oprimido (1894-1897) y L'Avvenire (1896-1904), entre otros.

El Oprimido fue editado por el irlandés Creaghe, quien contaba con una trayectoria militante más larga que la de Ingenieros, en tanto le llevaba al joven estudiante 36 años. Graduado como médico cirujano en Royal College of Surgeons en Dublín, Creaghe emigraba por primera vez a Argentina en 1874 y hasta 1890. En este primer período tuvo contacto con el italiano Enrique Malatesta y participó de la edición del periódico anarquista La Verdad. En 1890 Creaghe viajaba a Inglaterra en donde, luego de una breve participación en la liga socialista de William Morris, se separaba de ella para formar el grupo "Los anarquistas de Sheffield" y el periódico Sheffield

\footnotetext{
${ }^{6}$ Este centro socialista se constituyó el 1 de junio de 1895, a instancias del Centro Socialista Obrero (ex Agrupación Socialista). Participaron de sus inicios Ricardo Cardalda, Francisco Cardalda, Ramón Potau, Benigno Abriani, Salvador Lotito, Manuel Berenguer, Felipe R. Palancas, Juan Toulousse, Antonino Piñero y Arturo Roqueta. Radicado en la calle Australia 1131 (Barracas al Norte), barrio de obreros y de inmigrantes, este local constituyó un espacio central del apoyo socialista a la huelga de los ferroviarios. Asimismo, a partir de 1896, fue lugar de reunión para Ingenieros y Lugones, desde donde emprendieron una actividad de propaganda y difusión de su tendencia izquierdista.
} 
Anarchist. En 1892 el médico regresa a Argentina para instalarse en la cuidad de Luján donde, además de ejercer su profesión, organizaba múltiples actividades de propaganda entre los obreros. Durante estos años estuvo suscripto y fue un referente importante del periódico El Perseguido, el cual publicaba noticias sobre la actividad anarquista en Luján y difundía las conferencias y reuniones ${ }^{7}$ que Creaghe convocaba.

En 1894 el anarquista, en busca de posiciones más moderadas se aleja de $E l$ Perseguido y comienza a editar El Oprimido, el cual se redactaba en Luján pero se imprimía y era distribuido en Capital Federal por el italiano Fortunato Serantoni, que además publicaba La Questione Sociale. En 1896 La Questione Sociale, que publicaba artículos de Kropotkin Reclus, Bakunin, Malatesta, se convierte en suplemento literario bisemanal de $\mathrm{El}$ Oprimido. La orientación ideológica del periódico de Creaghe estuvo signada por la influencia de Kropotkin y Malatesta y abrió lugar a un debate sobre la moral anarquista, que fue parte importante de la polémica entre organizadores e individualistas. En este contexto, la posición moderada del anarquismo comenzaba a dar un giro en su posición frente a las huelgas. Creaghe, desde 1894 sostenía que la reivindicación de la violencia perjudicaba la propaganda anarquista y que, dado que la huelga conformaba un fenómeno inevitable, resultaba más conveniente involucrarse en ellas para radicalizarlas e incentivar a los trabajadores en la lucha por la revolución social. Además de la actividad anarquista llevada a cabo en Luján, Creaghe participaba de asambleas en otro gran centro de propaganda anarquista El Prado Español, que nucleaba a los obreros panaderos que también adhirieron a la gran huelga.

Estas tentativas plasmadas en El Oprimido y los restantes periódicos confluirán en 1897 con la aparición del periódico La Protesta Humana. Por cuestiones ideológicas y económicas, Creaghe decide dejar de publicar El Oprimido y unirse a La Protesta Humana, al cual prestará gran apoyo económico y moral, siendo su administrador y director en varios períodos. El primer director del periódico fue Gregorio Inglán Lafarga y entre sus primeros y más conocidos colaboradores se destacaron José Prat, Eduardo Gilimón, Mariano Cortés, Antonio Pellicer Paraire y Alberto Ghiraldo. La Protesta Humana configuró uno de los periódicos más importantes del anarquismo argentino; además de contribuir en la consolidación de la línea organizadora, este periódico también tuvo un papel importante en el incremento de la participación anarquista en la actividad sindical de los obreros, principalmente a través de su vínculo con la FORA ${ }^{8}$. La decisión centralista de unificar todas las voces en un solo

\footnotetext{
${ }^{7}$ El 11 de noviembre de 1893, El Perseguido publica, en la página principal, un incidente sucedido en Luján que tuvo a Creaghe como protagonista. Los anarquistas habían convocado a una conferencia el 29 de octubre anunciada "Ni Dios ni patria. Conferencia comunista anárquica". Un momento antes de la hora de la reunión, el comisario de la localidad se presentó en el domicilio del médico creyéndolo iniciador y director de la reunión y le manifestó que tenía orden superior de su jefe para no permitir que se efectuara la reunión. La reunión se inició de todos modos pero fue sorprendida por un comisario acompañado de un grupo de vigilantes armados. Creaghe regresó a su domicilio pero a la noche allanaron la casa y lo detuvieron. Los anarquistas que habían ido desde otros lugares a la conferencia también fueron apresados en la estación de tren, lo cual generó un pedido de ayuda para poder liberarlos.

${ }^{8}$ fundada el 25 de mayo de 1901 con el nombre de Federación Obrera Argentina y denominada FORA en 1904, constituyó una organización intersindical que nucleó a diferentes sociedades obreras, inicialmente socialistas y anarquistas. Esta coexistencia resulto una contradicción muy grande al interior de la Federación, lo cual condujo a la escisión de los socialistas en 1904. La presencia del anarquismo en la FORA fue dominante hasta 1915.
} 
periódico, era contrario al ideal que pregonaban los individualistas en tanto creían que atentaba contra las libertades individuales. Del mismo modo, los individualistas se opusieron firmemente a la creación del Círculo Internacional de Estudios Sociales ${ }^{9}$, alegando que todo tipo de organización suponía el principio de autoridad.

Creaghe además de participar de la creación de La Protesta Humana y brindar un sostén económico, publicaba artículos en La Ciencia Social. Revista de Sociología, Artes y Letras (1897-1901), diario de la Librería Sociológica, también editado por Serantoni y en el cual escribían anarquistas como Kropotkin, Jean Grave, Eliseo Reclus, José Prat, Esteban Gori, y Molina y Vedia.

Este clima de agitación y movilización fue casi paralelo a la celebración del primer Congreso constituyente del Partido Socialista, en junio de 1896, y justamente el uso de la fuerza como método para realizar la revolución constituyó uno de los factores que enfrentaron a Ingenieros y a Lugones con Justo. La propuesta que había redactado Justo en la "Declaración de Principios" para el congreso, fue la de establecer la acción política y la asociación libre como medios para llevar a cabo la revolución. En ese documento, Justo denominaba revolución ${ }^{10}$ a la transformación perseguida, la cual consistía en establecer una sociedad basada en la propiedad colectiva de los medios de producción, en la cual cada trabajador fuese dueño del producto de su trabajo. Este nuevo orden, para Justo, fundaba una organización científica de la producción y una moral social que venía a reemplazar la anarquía económica y el egoísmo. En este contexto, la vía parlamentaria resultaba, para Justo, el único camino adecuado para llegar al poder político y desde allí realizar la transformación, en cambio, se apelaría a otro medio de acción "si las circunstancias se lo imponen".

Ingenieros y Lugones, en cambio, defendieron en el Congreso no sólo la vía parlamentaria sino también la acción reivindicativa, en tanto "medios de agitación, propaganda y mejoramiento que servirán para preparar esa fuerza" (1896:167). Asimismo, los jóvenes propusieron agregar un enunciado adicional: "que por este camino el proletariado podrá llegar al poder político, constituirá esa fuerza y se formará una conciencia de clase, que le servirán para practicar con resultado otro método de acción cuando las circunstancias lo hagan conveniente" (1896:362). Para Ingenieros la acción política y la organización para la resistencia constituían una especie de momento de preparación anterior al momento revolucionario que se produciría cuando estuviesen dadas las condiciones. En este sentido, ese "otro método de acción" denotaba el momento insurreccional, el cual parecía inevitable y no una excepción como lo era para Justo en su afirmación "si las circunstancias se lo imponen". La modificación fue votada por la mayoría y, de este modo, quedó establecida esta concesión respecto del uso de la fuerza. No obstante, la permanencia de tal enmienda será breve ya que en el segundo congreso de 1898, una vez

\footnotetext{
${ }^{9}$ Su programa fundacional se da a conocer a través de La Protesta Humana, en agosto de 1897. Entre sus objetivos señalan la necesidad de una propaganda activa entre los trabajadores, la igualdad de los seres humanos y de los sexos, la lucha contra la autoridad y la religión, la consideración de que las riquezas sociales son el resultado del trabajo común, y la idea de que el objetivo de todos los esfuerzos debe ser la revolución.

${ }^{10}$ Falcón en "Notas sobre la formación de la identidad socialista en Argentina" señala que Justo mantenía la misma interpretación sobre el concepto de revolución dominante en la II Internacional, según el cual el partido socialista era revolucionario por la magnitud de las transformaciones que perseguía.
} 
consolidada la posición de Justo como hegemónica dentro del Partido, se suprimirá el párrafo final de la Declaración de Principios.

En abril de 1897 comienza a publicarse el periódico La Montaña. La disposición de la publicación consta de tres secciones o columnas: "Estudios sociológicos", "Arte, filosofía, variedades" y "Actualidad". La primera sección incluye colaboraciones de carácter principalmente científico, y relativas al socialismo. Entre ellas encontramos artículos de Loria, Ferri, Gabriel Deville, algunos párrafos extraídos de los textos de Carlos Marx, Paul Lafargue, Jules Guesde, August Bebel, entre otros. En la segunda sección se publican poemas de Lugones y Felipe Turati, fragmentos de Luis Blanc, poesías de Rubén Darío, Ada Negri y el francés Adolphe Retté. La tercera sección se centra en el comentario crítico sobre ciertos acontecimientos y costumbres de la vida social y política burguesa, realizados desde categorías morales.

En el segundo número del periódico se incorpora la sección "Bibliografía", a través de la cual se divulgan periódicos, libros y folletos enviados desde diferentes países y ciudades, "emitiendo un juicio sobre los que lo merezcan" (1897:53). Como señala Tarcus (2009/2011), el periódico atraía a los jóvenes interesados no sólo en el socialismo sino también en el modernismo literario. Chile y Uruguay ${ }^{11}$ fueron los países donde La Montaña produjo un mayor impacto, en gran medida por la presencia del modernismo en estos países. A nivel nacional los redactores de $L a$ Montaña manifiestan contar con el apoyo de Rubén Darío, Carlos Malarriaga, Macedonio Fernández, Julio Molina y Vedia, Alfredo Palacios, Enrique Dickman, entre otros. Entre las figuras internacionales ${ }^{12}$ reivindicadas con mayor énfasis están los italianos Antonio Labriola, Felipe Turati y el francés Jean Allemane y su publicación Le Parti Ouvier. En su último número, la sección "Bibliografía" del periódico nombra entre sus lectores y colaboradores a Eliseo Reclus, Auguste Vaillant, Abate Garnier, Spring Walley, Charles Parisis, Henry Malatesta, entre otros.

Una especie de manifiesto titulado "Somos socialistas" abre el primer número del periódico, allí se explicitan las bases de su orientación política: la implantación de un sistema en el cual "los medios de producción estén socializados; en que la producción y el consumos se organicen libremente (...)" (1897:11) y "la supresión del Estado y la negación de todo principio de autoridad" constituyen los puntos principales. Con ellos, Ingenieros y Lugones definen un socialismo revolucionario e intransigente basado en un antiestatismo radical. A diferencia de La Vanguardia, que propone fomentar la acción política de los trabajadores para conseguir reformas

\footnotetext{
${ }^{11}$ Entre las Revistas chilenas que son anunciadas en esta sección cabe destacar a El Pueblo, editada en Valparaíso por el médico Mario Centore; la redacción de La Montaña, en el tercer número, agradece el afectuoso saludo enviado desde las páginas de la revista de Valparaíso. Además, la revista chilena de literatura modernista Tacna, dirigida por José María Barreto, es anunciada en la mayoría de los números del periódico. En el caso de Uruguay, la redacción de La Montaña anuncia el número 50 de la Revista Nacional de Literatura y Ciencias Sociales, editada en Montevideo por Víctor Pérez Petit y José Enrique Rodó.

${ }^{12}$ Entre las revistas de origen europeo se destacan la revista socialista marxista Social Democrat de Londres, que es valorada por La Montaña en virtud de los artículos de Vandervelde y de Carlos Marx. La revista mensual de literatura modernista Neuland, de Berlín, La ilustración Popular, de Madrid, la cual reproduce artículos de La Montaña, y una enorme cantidad de revistas socialistas francesas que son anunciadas sin comentario alguno: La Revue Socialiste, La Revue Blanche, Le Devenire Social, Le Jura Socialiste.
} 
concretas dentro del régimen vigente, en La Montaña no existe algo siquiera próximo a un programa de acción.

\section{La Revolución}

El reformismo parlamentarista de Justo no sería el principal interlocutor para Ingenieros y Lugones en la polémica sobre los medios de acción. En tanto esta discusión había dividido al anarquismo en dos sectores, los jóvenes socialistas encontrarían en los periódicos anarquistas un terreno de interés para continuar delimitando su postura. Curiosamente, en relación a la prensa y literatura anarquista, en el segundo número de La Montaña se presentan tres libros: Entre campesinos, de Malatesta, La Anarquía, su filosofía y su ideal de Kropotkin-al que la redacción critica por la falta de correspondencia entre el título y el contenido-, y Psicología del anarquista-socialista de A. Hamon. Asimismo, La Montaña anuncia diversas publicaciones anarquistas; en particular, la revista Ciencia Social, en la que colaboraba Creaghe, y que es destacaba por los artículos de Julio Molina y Vedia, de Edward Charpenter y de Jean Grave. La Autonomía "periódico libertario, amoral y antiorganizador" (1897:154), La Protesta Humana y el periódico italiano L'Agitazione también se anunciarán de modo recurrente.

El artículo "Anarquistas y socialistas", fue el punto de partida para la discusión con el anarquista Creaghe. Allí Ingenieros se incorpora en el debate, que aún atravesaba al anarquismo, entre los sectores organizadores y los anti-organizadores, el cual aparece representado por dos periódicos diferentes: L'Avvenire, representante del primer grupo, y La Autonomía, del segundo. El objetivo del joven socialista en este artículo consiste en establecer afinidades entre su propuesta revolucionaria y el sector del anarquismo defensor de la organización, a fin de marcar la evolución de este último hacia el socialismo. Por esta razón, toma como punto de partida una coincidencia que advierte entre ambas corrientes respecto del objetivo último "tanto anarquistas como socialistas coinciden en la aspiración final: $1^{\circ}$ socialización de la propiedad; $2^{\circ}$ Supresión del Estado" (Ingenieros, 1987:147).

No obstante, Ingenieros señala dos aspectos en los cuales el anarquismo y el socialismo marcan sus distancias. En primer lugar, existe una diferencia respecto de las lógicas a través de las cuales cada grupo concluye en la necesidad de la transformación. En este sentido, el socialismo supone que el Estado es un efecto de la propiedad individual y que fue creado para conservarla, con lo cual, al suprimir la propiedad individual desaparecería el Estado. En cambio, desde la perspectiva del anarquismo la propiedad constituye un efecto del Estado y por ello es necesario suprimir al último para que la primera desaparezca. Sin embargo, Ingenieros aclara que se trata de lógicas convergentes ya que la diferencia es sólo dialéctica, lo cual no amerita establecer una distancia absoluta entre ambas teorías.

En segundo lugar, el joven socialista detecta una diferencia en relación a los métodos de acción. Sin embargo, Ingenieros sostiene que esta diferencia sólo es tal en el caso de los anarquistas que repudian cualquier tipo de organización. La creciente tendencia de ciertos grupos anarquistas a apoyar la organización es interpretada por el socialista como una evolución del anarquismo hacia el socialismo, como la progresiva adopción de la táctica socialista. El artículo finaliza del siguiente modo: 
Y volviendo a los periódicos citados demos un apretón de manos a L'Avvenire que de la táctica anarquista evoluciona, permaneciendo antiparlamentario, hacia la táctica socialista, mientras que reconocemos en La Autonomía al verdadero defensor de la táctica anarquista tal como siempre la hemos comprendido: libre iniciativa, atentados individuales, antiparlamentarismo (1897: 148).

En consecuencia, el verdadero adversario del socialismo aparecía representado por el sector individualista del anarquismo, defensor de la libre iniciativa ${ }^{13}$. Así, la figura del anarquista organizador se presentaba como alguien que estaba en camino hacia el socialismo: "No cabe la menor duda que esa salutable evolución de los anarquistas hacia el socialismo se extenderá cada vez más (...), y que la táctica socialista es más provechosa para la Revolución” (Ingenieros, 1897:147).

El 15 de agosto se publica en La Montaña una nota firmada por Creaghe, escrita el 23 de julio, en la cual, a lo largo de 13 puntos, refuta uno a uno los comentarios desarrollados en el artículo "Socialistas y anarquistas". El anarquista le cuestionaba a Ingenieros el presunto carácter revolucionario de su tendencia: “¿cómo es posible que uno que se llame revolucionario tome parte en las luchas de los partidos burgueses sin echar en olvido la lucha de clase? Una vez que tome parte en la política reconoce prácticamente el sistema social existente con todas sus abominaciones, (...)” (Creaghe, 1897:244).

El 1 de agosto La Protesta Humana publica en la sección "Reuniones", una reflexión sobre una reunión de controversia entre socialistas y anarquistas, desarrollada durante los días 17 y 18 de junio, cuyo tema de discusión se había centrado en la acción política. Desde La Protesta Humana expresaban:

Consideramos nosotros, los anarquistas, que la única táctica que puede dar resultados satisfactorios y acelerar la deseada emancipación, es la táctica revolucionaria; la abstención electoral, la huelga militar, la huelga general, la agitación y la propaganda netamente revolucionaria, táctica a la cual recurrirán los socialistas de buena fe, cuando como muchas fracciones socialistas, se convenzan de que la acción política que consiste en aburguesar a unos cuantos obreros y fiar la obra de la emancipación en ellos les está dando resultados negativos (1897:4).

Esta "táctica revolucionaria", sin embargo, irá moldeándose progresivamente hasta encontrar la forma adecuada que permitiese al anarquismo lograr una intervención sólida en el movimiento obrero sin perturbar el valor anarquista de la libertad. Como veremos en el próximo apartado, esto conducirá al anarquismo a redefinir el fundamento de su nueva propuesta. No obstante, la acción política parlamentaria será, en todo momento, el límite que el anarquismo encontrará en su proceso de transformación.

La cuestión de los métodos de acción es retomada por Ingenieros en otro artículo de La Montaña titulado "El factor de la revolución", publicado en el mes de abril. Ingenieros presenta al capitalismo como un estadio necesario en la historia de la evolución, que comienza con el salvajismo, pasando por la barbarie, hasta llegar a la

\footnotetext{
${ }^{13}$ La táctica individualista era rechazada por La Montaña en una carta firmada por la redacción, en la cual se expresa el rechazo por los atentados individuales y, en cambio, una defensa respecto de la necesidad de la lucha política: "los socialistas preconizamos la organización para la lucha, creemos tan fatales como inútiles los atentados individuales, y demostramos con la argumentación irrefutable de los hechos que la participación en la lucha política es un excelente medio de propaganda, agitación y mejoramiento" (1897:196).
} 
civilización. El joven socialista advierte allí que el sistema de producción capitalista encierra los elementos de un nuevo sistema de producción, y por eso el pasaje hacia el socialismo se realizaría mediante la expropiación del pequeño número de poseedores del capital. En este contexto, la idea de revolución aparece, en primera instancia, sólo como una posibilidad, aunque luego resulta casi inevitable: "La revolución social obedece, en primer término, a un cambio en el sistema de producción. Si la clase privilegiada fuese inteligente -caso imposible porque el parasitismo trae consigo la degeneración- se adaptaría estoicamente a ella" (1897:20). No obstante, argumenta Ingenieros, la burguesía va a oponerse a este cambio en el sistema de producción, y entonces "el proletariado usará la fuerza para expropiar a los expropiadores. No puede haber en este caso dos líneas de conducta: la fuerza se combate con la fuerza" (1897:20).

En aquel artículo el socialista parecía introducir una concesión para evitar el uso de la fuerza -que la burguesía comprendiese el cambio-, para luego negarla, ya que la burguesía estaría determinada por esa ignorancia. Como consecuencia, la revolución resultaba inevitable, el único modo de poseer los medios de producción en común sería a través de la fuerza. Este artículo dejaba al descubierto las contradicciones entre, por un lado, la confianza de Ingenieros en el desenvolvimiento de una evolución natural hacia el socialismo por la fuerza de las condiciones económicas, y por otro lado, el carácter inevitable de una revolución violenta como producto de la ignorancia casi natural de la burguesía.

No obstante, estas tensiones comenzaban a atenuarse en otros dos artículos publicados posteriormente también en La Montaña. En "Socialismo y Revolución", del mes de julio, Ingenieros reivindica la revolución como el método adecuado para lograr la socialización de todos los medios de producción, la supresión de las clases sociales y, por ende, la desaparición del Estado. Asimismo, considera que la revolución constituye una característica esencial del socialismo, "Ser o no ser. Socialista y revolucionario son dos cualidades inseparables" (Ingenieros, 1897:163). Sin embargo, lo revolucionario aparece en este artículo asociado a la pretensión del objetivo: la socialización de los medios de producción. Revolucionario es, para Ingenieros, "aquel que aspira a realizar la Revolución, es decir aquel que aspira sustituir el sistema de producción capitalista vigente" (1897:163).

Finalmente, en "El individuo y la sociedad", publicado en el número 7 del 1 de agosto, Ingenieros realiza una reseña crítica sobre el libro del anarquista francés Jean Grave El individuo y la sociedad. Ingenieros sostiene en su artículo que la idea de revolución defendida por el anarquista entra en contradicción con sus ideas expresadas en otros escritos. Lo interesante es que allí el socialista recupera y reivindica la definición sobre la idea de revolución que Grave sostiene en otras obras; según esta concepción, la revolución es un fenómeno social que resulta de la evolución del ambiente natural y económico y consiste en la transformación de una forma de organización social en otra más armónica con las nuevas condiciones del ambiente. Sin embargo, en el libro reseñado, Ingenieros encuentra que, en contradicción con lo anterior, el anarquista mantiene posiciones individualistas ${ }^{14}$ sobre la revolución; esto es, que los progresos logrados por los hombres se producen

\footnotetext{
${ }^{14}$ Ingenieros señala que Grave sostiene la misma posición que critica, ya que considera que sería una minoría quien debería impulsar ese conjunto de rebeliones, arrastrando al pueblo en ese mismo movimiento. Esto, para Ingenieros, resulta una demostración del mismo autoritarismo que el propio autor pretende combatir.
} 
en virtud de la rebelión, en tanto "exteriorización más elevada de la conciencia individual contra la opresión de la conciencia colectiva" (Ingenieros, 1897:217). Según Ingenieros, en su pretensión por oponerse al socialismo, Grave terminó distorsionando las coincidencias que presentaba con la concepción socialista de la revolución en los primeros escritos, lo cual le provocó contradicciones en el interior de su propio sistema. En tanto aclara que un conjunto de rebeliones no conforman una revolución, el joven socialista asume su rechazo respecto del uso de la violencia y su proximidad a concepciones evolutivas sobre la revolución.

De esta manera, Ingenieros desligaba la idea de revolución con el uso de la fuerza y, asimismo mitigaba la contradicción entre la inevitabilidad del socialismo y el carácter voluntarista de la revolución entendida como un momento concreto en el cual se modificaría el estado actual. En definitiva, la idea de revolución parecía referirse a la pretensión de un cambio, lo cual volvía inútil el uso de la fuerza como herramienta de lucha, y lo acercaba a la formulación de Justo en la "Declaración de principios" del Congreso de 1896. Allí, como vimos, la revolución aparecía asociada a la pretensión de una transformación económico-social, llevada a cabo por la clase trabajadora y en favor de la misma. La organización política de los trabajadores para acceder al poder y a partir de allí realizar el cambio fue la táctica propuesta por Justo y en este sentido no había espacio para el momento insurreccional.

En $1899^{15}$ Ingenieros abandonaba su militancia en el Partido Socialista y continuaba acercándose a posiciones gradualistas sobre la revolución que interpretaban la llegada del socialismo como el producto de una progresiva sucesión de reformas. El uso de la fuerza tampoco constituyó, en ese entonces, una herramienta de lucha habitual y permanente entre los anarquistas; incluso entre los sectores anarcoindividualistas el recurso a la violencia permaneció más en el plano discursivo que en la realidad (Suriano, 2008:279). La táctica anarquista, por el contrario, estuvo centrada fundamentalmente en la propaganda y difusión de la idea libertaria con el fin de concientizar al pueblo de la necesidad de una transformación que se produciría de forma espontánea. Por último, la defensa del joven socialista respecto del momento insurreccional como medio para instaurar la sociedad socialista, se desvanece rápidamente a lo largo de los artículos publicados en un periódico cuya duración no superó los seis meses.

\section{Libertad y Autoridad}

En la carta publicada en La Montaña, Creaghe establece un vínculo entre la cuestión de los medios de acción y las lógicas que rigen a cada sector. En este sentido, el anarquista señala que el factor determinante para definir la táctica revolucionaria es

\footnotetext{
${ }^{15}$ Ese mismo año, en la conferencia "La jornada de Trabajo" Ingenieros afirma "Esta transformación no puede operarse sino de una manera progresiva y constante, por un proceso de integración gradual, mediante la sucesión de reformas y conquistas que irán paulatinamente convirtiendo en Hecho la Idea (...)" (1899:6). Esta concepción procesual del socialismo termina de definirse en 1906 en el artículo "Socialismo y legislación del trabajo" en el cual sostendrá "Conviene, pues, al socialismo abandonar ciertas exageraciones violentas, otrora exigidas por las masas como condición de su aplauso y de sus votos. Se advierte entre sus elementos pensantes la necesidad de adaptarse al régimen económico actual, y perseguir dentro de él reformas reales (...)" (Ingenieros, 1908:14).
} 
el modo de concebir la cuestión social y, en este punto, anarquistas y socialistas adoptan posiciones completamente opuestas. En tanto la cuestión social es concebida por el anarquismo, no desde un punto de vista económico como según él lo hace el socialismo, sino como una cuestión de libertad, así los pares de oposiciones se dirimen entre libertad absoluta y autoridad de la mayoría. Creaghe sostiene que el Estado no constituye un producto de la propiedad privada como pretenden los socialistas sino al revés: el Estado al controlar y reglamentar la producción de los trabajadores limita la libertad individual y conduce a la esclavitud, por ello, la cuestión social resulta una cuestión de libertad.

Sin embargo, Creaghe, no sólo se centra en marcar las diferencias respecto a las lógicas sino que, además, cuestiona la identidad de fines entre el socialismo y el anarquismo propuesta por Ingenieros. En efecto, el anarquista sostiene que una vez instaurada la sociedad socialista ésta no permitiría la realización de la libertad sino que se impondría la autoridad de la mayoría y por ende, los parlamentos y el Estado, "la diferencia es que reclamamos toda la libertad, creyendo que menos que toda no es nada -la Libertad no admite restricción-" (Creaghe, 1898:243). A partir de esta definición, Creaghe critica la concepción acerca de la libertad expresada por Paul Lafargue en un artículo publicado el 15 de julio en La Montaña, según la cual los obreros serían libres cuando los medios de producción pertenecieran al productor (1897:189), ya que de ese modo sólo necesitarían unas pocas horas de trabajo y en el resto del tiempo podrían "reposar y pertenecerse". El anarquista deduce de lo anterior que los obreros, durante la tarea exigida, pertenecerían a los gobernantes socialistas quienes reglamentarían la producción y, por ende, al productor; lo cual implicaría dejar la puerta abierta a la tiranía.

Pero, si la libertad concebida por el anarquista revestía un carácter absoluto, es decir, implicaba la ausencia total de cualquier tipo de autoridad entonces la cuestión a resolver consistía en cómo evitar el conflicto entre las diferentes libertades individuales. En El Oprimido Creaghe consideraba que no haría falta ningún tipo de regulación entre los individuos de la sociedad anárquica en virtud de la existencia de una razón universal que garantizaría que todos los individuos actuasen del mismo modo $^{16}$. En La Protesta Humana, por el contrario, esta posición será refutada. En el número 6 del periódico, fechado el 2 de septiembre de 1897, se publica una nota titulada "Del individualismo en el anarquismo", donde se critica la idea de "armonía por ley natural", atribuida ahora al anarquismo individualista, la cual permitiría conciliar el principio de la absoluta libertad individual con el bien común de toda la sociedad: "Destruid el estado y la propiedad individual, dicen los anarquistas individualistas, y todo irá bien, todos marcharán naturalmente de acuerdo. Así que, yendo al fondo del asunto, hallamos que el anarquismo individualista no es otra cosa que una especie de armonismo de providencialismo" (1897:1).

El periódico defiende la idea de que, al contrario de lo que argumentaban los individualistas, resultaba posible la organización sin autoridad, “(...) entendiéndose

\footnotetext{
${ }^{16}$ En El Oprimido Creaghe sostenía: "Será libre cada uno a determinar para sí lo que debe hacer, pero la razón es una, es igual entre los hombres y resultará que cada uno se comportará de la misma manera como los otros, en un tiempo será tan habitual comportarse así en una sociedad comunista-anárquica, en donde no habrá lucha de intereses, que se perderá la palabra deber (1894:4)". El anarquista contraponía la artificialidad de la sociedad creada sobre el principio injusto a la naturalidad de la sociedad anarquista, en la cual los individuos se hallan libres de sanciones y obligaciones, y se comportan de acuerdo a los dictados de su propia razón.
} 
por Autoridad la facultad de imponer la propia voluntad". El 21 de noviembre se publica un artículo titulado "La Organización", en el cual señalan que la organización constituye el principio y la condición de la vida social y, sobre todo, la garantía de las libertades individuales:

Sin organización consciente y querida no puede haber ni libertad, ni garantía alguna de que los intereses de los que vivan en sociedad sean respetados. Y el que no se organice, quien no busque la cooperación de los demás y ofrezca la propia en condición de reciprocidad y de solidaridad, se coloca necesariamente en estado de inferioridad (1897:1).

Asimismo, en el número 15 de La Protesta Humana, del 21 de noviembre, advierten explícitamente la imprescindible organización de un Partido anárquico "Nosotros entendemos por Partido Anárquico el conjunto de aquellos que quieren contribuir a actuar la anarquía, y que para esto tienen necesidad de trazarse un objetivo para realizarlo y un camino para seguirlo (...) Permanecer aislados es condenarse a la impotencia". A partir de esta organización al interior del anarquismo concluyen la necesidad de una organización general de las masas obreras para la resistencia contra el gobierno y contra los patrones, lo cual supone apoyar organizaciones obreras de toda clase, no sólo aquellas que tuviesen como objetivo directo la anarquía. De este modo, hacia fines de 1897 se consolidaba la corriente organizadora que será dominante en el anarquismo hasta 1910.

Ingenieros, por otro lado, en "El arte de la sociedad futura" propone una concepción relativa sobre la libertad, en tanto que la subordina al concepto de posibilidad: "se puede ser libres, dentro de una órbita determinada, cuando es posible hacer todo lo que se encierra dentro de ella" (Ingenieros, 1895:45). El joven socialista denuncia que en su actualidad la libertad es sólo formal en tanto predomina la imposibilidad de realizarla. Esto se debe a la existencia de un sistema socio-económico que beneficia a unos pocos individuos en detrimento del resto. En la misma línea, el primer número de La Montaña anunciaba: "queremos al individuo libre de toda imposición o restricción económica, política y moral, sin más límite a su libertad que la libertad igual de los demás" (1897: 11). Según Ingenieros, el socialismo aportará el máximo de libertad ya que le otorgará a cada individuo la posibilidad de hacer lo que desee, sin perjudicar a los demás. Con esto, el socialismo suprimirá la libertad burguesa de explotar: "marchando del sistema presente hacia el socialismo, la humanidad marcha de la esclavitud a la libertad" (Ingenieros, 1895:50).

En el mismo número en que se publicaba la carta Creaghe, aparecía a continuación una nota titulada "Observaciones a la carta precedente", firmada por la redacción. Allí Ingenieros persiste en reafirmar la identidad de fines con el anarquismo. El joven socialista reivindica la necesidad de la destrucción del Estado y, para reforzar el argumento, alude a los artículos publicados en números anteriores sobre la cuestión: uno del francés Gabriel Deville "La sociedad sin Estado" y otro de Augusto Bebel "La evolución del Estado". En el escrito, Deville define al Estado como "el poder público de coerción que la división en clases crea y mantiene dentro de las sociedades humanas, y que, disponiendo de la fuerza, hace la ley y percibe el impuesto" (1897:12). Si examinamos los artículos de Deville, podemos observar que de allí Ingenieros retoma la idea según la cual resulta indispensable suprimir las

\footnotetext{
${ }^{17}$ Fue uno de los introductores del marxismo en Francia a través de su resumen del Tomo I de $E l$ Capital y su actividad en el Partido Francés de los Trabajadores, de Jules Guesde, fundado en 1879.
} 
clases sociales para suprimir el Estado. Asimismo, Ingenieros reitera la finalidad para el socialismo de la socialización de los medios de producción y la libre organización de los individuos productores, sin necesidad de gobierno alguno.

En la nota dirigida a Creaghe, Ingenieros esbozaba un criterio para regular la producción basado en el factor natural: "organizarla (la producción) de acuerdo con aquellas reglas fundadas en las ciencias naturales que aseguren un máximum de producción con un mínimum de esfuerzo; es muy probable que los productores lo hagan satisfaciendo su propia conveniencia" (1897:245). Esta libre organización, sin embargo, tenía un límite en las necesidades colectivas; en la declaración inicial de La Montaña señalaban "Porque luchamos por la implantación de un sistema (...); en que el consumo y la producción se organicen libremente de acuerdo con las necesidades colectivas por los productores mismos para asegurar a cada individuo la mayor suma de bienestar..." (1897:11). La existencia de algún tipo de organización para la sociedad socialista pareciera confirmarse en Ingenieros más aún si examinamos nuevamente lo expresado por Deville: "Esto no quiere decir que la sociedad socialista carecerá de organización. Sólo que la organización social futura (...) no será un Estado, ni serán capital los medios de producción (...) ni será lo que se llama salario la manera de retribución del trabajo" (1897:66). Respecto al criterio y modos de organización específicos ni Ingenieros ni Deville brindan una definición específica.

Tanto Ingenieros como Creaghe terminaron admitiendo la necesidad de algún tipo de organización como modo de garantizar las libertades individuales. Sin embargo, Creaghe consideraba que la libertad "parcial" defendida por los socialistas, los habría conducido a defender la participación política, lo cual implicaba para el anarquista una aceptación del sistema social vigente, de la lucha de clases y de la esclavitud del proletario productor.

En efecto, el carácter de clase del partido, que unía a los socialistas entre sí y los diferenciaba del anarquismo, los había enfrentado al momento de discutir sobre la cuestión de las alianzas políticas en aquel congreso de 1896. Lugones e Ingenieros propusieron mantener la intransigencia del partido, lo cual se oponía al proyecto original que aceptaba las alianzas, siempre que se respetara el programa. Por mayoría de votos triunfó la propuesta de la corriente revolucionaria "serán excluidos del Partido las colectividades o individuos que hagan pactos o alianzas con los partidos burgueses o con sus candidatos" (Justo: 1896:361), aunque esta enmienda sólo durará hasta 1898. No obstante, la medida que lograron establecer desde aquel carácter izquierdista de la tendencia no logró acercarse a la posición anarquista que rechazaba cualquier tipo de acción política. En la medida en que, como señala Juan Suriano, la idea de libertad constituyó para el anarquismo un derecho natural inherente al hombre, la denuncia se centró en las formas de opresión que turbaban ese derecho, antes que en el antagonismo de clases. Por esto, la interpelación anarquista se dirigió hacia los "oprimidos" más que a la clase obrera en particular.

Por último, el reflejo más claro del viraje de Creaghe hacia la organización consistió en su vinculación con la FORA a través de La Protesta Humana, la cual, a partir de 1904 será vocera no oficial de dicha organización. Desde 1904 el periódico se convierte en diario gracias a la adquisición, por parte de Creaghe y otros colaboradores, de una imprenta propia y pasa a llamarse La Protesta. La mayor frecuencia en la tirada les permitía comunicar y divulgar con mayor frecuencia los 
postulados de esta Federación que se opuso a la política parlamentaria y, en cambio, se enfocó en las reivindicaciones económicas.

\section{La cuestión moral}

Como mencionamos anteriormente, Creaghe había sido uno de los propulsores del debate sobre la moral anarquista desde las páginas de El Oprimido, que formó parte importante de la polémica entre individualistas y organizadores. En este periódico, Creaghe contraponía la falsa moral capitalista a una moral natural, fundada en una razón universal, libre de obligaciones y sanciones: "la verdadera moral anarquista es la que nos enseña la razón”. En la sociedad anarquista cada individuo, atendiendo a los dictados de la razón, sería capaz de determinar por sí mismo aquello que debía hacer en cada circunstancia, respetando la libertad del otro.

En La Protesta Humana, esta identificación de la moral anarquista con la idea de una moral natural que resulta degradada en el marco de la sociedad capitalista, continua vigente. Sin embargo, el rechazo hacia el principio individualista de una armonía natural capaz de garantizar espontáneamente el mutuo respeto de las libertades, condujo a los anarquistas representados en La Protesta Humana a buscar formas de contribuir al desenvolvimiento de esa moral natural.

En este sentido, a partir del número 8 del periódico, fechado el 8 de octubre, se anexa un folletín titulado La Moral anarquista de Kropotkin, traducida por Prat. El fundamento de la moral es colocado por Kropotkin en la idea de solidaridad o apoyo mutuo, entendida como una ley de progreso que rige las sociedades naturales: "En toda sociedad animal la solidaridad es una ley de la naturaleza (...). Cuanto más desarrollado está el principio de la solidaridad igualitario en una sociedad animal y convertido al estado de hábito, más probabilidades tiene de sobrevivir y salir triunfante de las luchas contra las intemperies y contra sus enemigos". En el caso de las sociedades humanas, la práctica de la solidaridad se ve opacada por las instituciones actuales. Sin embargo, "Desembarazándose de la Ley, la Autoridad y la Religión, la humanidad toma de nuevo posesión del principio moral que se había dejado arrebatar". El criterio o máxima a seguir en la determinación de la maldad o bondad de los actos particulares radica en el principio "trata a los demás como quieras ser tratado por ellos en circunstancias análogas”, el cual, según Kropotkin, se encuentra en todos los niveles de la sociedad natural.

En su intento por brindar una explicación sobre el origen del deber moral, Kropotkin apela a las ideas del francés Jean M. Guyau en Esbozo de una moral sin obligación ni sanción, en donde intenta construir una moral sin fundamento místico o sobrenatural. Según Guyau, el sentimiento del deber responde a un impulso vital: "es el sentimiento de su propia fuerza. Es la vida que rebosa, que busca extenderse". El progreso moral se produce en virtud del heroísmo, de la acción de aquellos individuos verdaderamente morales cuya fuerza los impulsa a brindarse a los demás sin pedir nada a cambio.

Kropotkin concluye que la moral anarquista no ordena normas ni ideales, sino que se convierte en una simple comprobación de hechos, una ciencia que invita a los hombres a escoger entre una vida monótona y una vida heroica, dedicada a luchar por el resto de los individuos "si sientes en ti la fuerza de la juventud, sé fuerte, sé 
grande, se enérgico en todo lo que tu hagas. Siembra la vida en torno tuyo. Observa que mentir, engañar (...) es reconocerte de antemano débil. Lucha para que sea permitido a todos vivir esta vida rica y exuberante (...)".

Ingenieros, en cambio, sostuvo un concepto positivo sobre la moral, que se caracterizó por ser relativo a cada espacio y tiempo particular, y a cada comunidad: "en sí mismo un acto no es moral ni amoral; según las condiciones del ambiente se lo juzga de uno u otro modo. Entre ciertos pueblos son actos amorales matar a los ancianos, vivir en poligamia, etc; entre nosotros son actos morales" (Ingenieros, 1897:215). Estas "condiciones del ambiente" que actuaban como determinantes de la moral de cada grupo referían al factor económico, determinante de todos los demás factores humanos. En tanto el joven socialista consideraba que estaban dadas las condiciones para la realización del socialismo, entonces el capitalismo configuraba un fenómeno artificial fundante de un orden inmoral ya que resultaba opuesto al orden que debía imponerse. Por eso, al modificarse el sistema económico desaparecería esta falsa moral: "porque creemos que a la supresión de todo yugo económico y político seguirá necesariamente la de la opresión moral, caracterizada por la religión, la prostitución, la ignorancia, la delincuencia, etcétera" (1897:11).

En este contexto, el socialismo constituyó, para Ingenieros, aquel orden que permitiría realizar el mayor bienestar, otorgando igualdad de condiciones a todos los individuos. Dado que el factor económico estaba determinado en última instancia por el factor biológico, la inmoralidad era tal por su antagonismo respecto de las leyes naturales. Para el joven socialista, la sociedad capitalista contradecía la ley biológica de supervivencia del más apto ya que no permitía que subsistiesen quienes desenvolvían sus aptitudes sino quienes poseían mejores medios de lucha, lo cual daba por resultado el parasitismo de unos pocos a expensas del trabajo de otros: "existe una perversión de la naturaleza humana producida por las presentes condiciones sociales que permite la inercia degenerativa de unos pocos a expensas de la laboriosa y agotadora esclavitud de la mayoría" (Ingenieros, 1895:50). En este sentido, la desigualdad resultaba una circunstancia artificial, contraria al orden natural que la ciencia mostraba.

A partir de esta concepción sobre la moral Ingenieros denunció, en un conjunto de artículos publicados en La Montaña, las costumbres de la sociedad burguesa: las visitas al santuario, las sociedades de beneficencia, los lujos excesivos, las costumbres políticas, todas ellas fueron criticadas por encubrir una falsa moral basada en la hipocresía, el interés y la especulación. En particular, Ingenieros denuncia en sus artículos el monopolio y el privilegio ético, siempre en beneficio de aquellos que redactan e imponen esa moral. En este sentido, expresa su repudio respecto de la "justicia" y el "derecho" burgueses, en relación a ciertos sucesos en los cuales las leyes no habían sido aplicadas por igual a burgueses y proletarios ${ }^{18}$.

Los tres artículos firmados por Ingenieros, "Los Reptiles burgueses" (I, II y III), constituyeron la vía a través de la cual el socialista denunció en su periódico la moral de una burguesía que, viciada por las ansias de riqueza, vivía a costa de la

\footnotetext{
${ }^{18}$ Tal fue el caso de la condena a prisión de la proletaria Alcira Boni por el asesinato a Pedro Intronich, dado que el juez consideró que ella violentó su pudor al mantener relaciones "ilícitas" con el agredido. Otro caso fue el naufragio del buque de guerra "Santa fe", provocado, según Ingenieros, por el capricho de un grupo de burgueses que intentaban dar un paseo con un grupo de señoritas, después de lo cual quedaron en libertad.
} 
opresión de demás: "El moralista burgués es siempre un cerdo que ha acumulado las células de su tocino destilando las lágrimas, el sudor y la sangre de la clase trabajadora (1897:121). De tal modo, “(...) todos los actos conceptuados inmorales son moneda corriente entre los moralistas" (Ingenieros, 1897:121). El tono provocador de estos artículos le costó la aplicación de una multa y el secuestro del segundo número del periódico, por parte del intendente municipal Francisco Alcobendas quien consideró ofensiva dicha publicación.

Según Terán, esta denuncia moral presente en La Montaña "no es ajena a la matriz conceptual del anarquismo". En efecto, un lenguaje similar recorría las publicaciones de La Protesta Humana, donde se dirigía una crítica, en términos morales, hacia todas las instituciones de la sociedad capitalista. El segundo número del periódico, con fecha 27 de junio, expresaba "La sed de robar, de chupar el sudor del pobre, jamás se había acentuado como actualmente, la religión, refutada y desmentida por la verdadera ciencia, (...); y nunca como ahora, la política perdió poderes morales y materiales, sin poseer la más leve esperanza de más tarde poder rehabilitarse"( 1897:2).

Sin embargo, esta denuncia al carácter inescrupuloso del capitalismo y el rechazo a los valores burgueses había sido una característica dominante también en el discurso del modernismo cultural $^{19}$, dominante en el campo estético-literario. Desde la corriente del modernismo la crítica se centró principalmente en los valores utilitarios de la sociedad capitalista, frente a los cuales opusieron el valor de la belleza. Desde 1893 Rubén Darío residía en Buenos Aires y la crítica moral a la burguesía pudo haber funcionado como vía de comunicación entre el modernismo literario y el socialismo de Ingenieros (Terán, 1986:15). La denuncia modernista hizo hincapié en la situación de marginalidad que el artista vivía dentro de la sociedad capitalista a causa del predominio del valor monetario por sobre el mérito artístico.

En La Montaña, Ingenieros relaciona la cuestión artística con la cuestión obrera al colocar al artista en una relación de paridad con el proletariado, en tanto considera que ninguno recibe la retribución que le corresponde: "junto al malestar del proletariado está el malestar de los que poseen como único material su inteligencia" (1895:15). En el primer número de La Montaña la redacción publica una nota titulada "Fundación de una colonia de artistas", desde donde se convoca a los artistas e intelectuales de todos los países a independizar al arte del mercantilismo burgués por el cual "a menudo hemos debido mendigar el pan ante los editores, los críticos, los aficionados y los diversos intermediarios (...)" (1897:22). Como contrapartida del intelectual, la imagen del burgués aparece identificada con la del mediocre, carente de buen gusto estético y aptitudes, que en su afán por aparentar cierto status "se ve forzado a codearse con gente bien para no sucumbir en los embates de la lucha por la vida" (Ingenieros, 1897:194). La aparición de este elemento modernista en La Montaña, presentado en relación a la explotación obrera, nos brinda razones para encontrar en el modernismo literario la principal fuente del carácter discursivo de Ingenieros.

Tanto Ingenieros como Creaghe consideraron que el orden vigente sólo permitía la realización de una falsa moral, opuesta a un orden natural. Mientras que para Ingenieros bastaba con modificar las condiciones económicas para la realización de

\footnotetext{
${ }^{19}$ Sobre modernismo cultural véase Real de Azúa (1986). Sobre Lugones y el modernismo véase Franzé (1997).
} 
aquel orden que las ciencias reflejaban en sus leyes, Creaghe y los anarquistas representados en La Protesta Humana, sostenían la necesidad de terminar con todo tipo de institución vigente para que pudiese aflorar la tendencia hacia la solidaridad innata en el hombre. A pesar de la negativa anarquista por imponer al individuo normas e ideales morales, es cierto que, en concordancia con la creciente tendencia hacia la organización, la argumentación de Kropotkin brinda, bajo la forma de una sugerencia, un modo particular de promover el desarrollo de la moral: la elección individual de llevar una vida heroica, fecunda e intensa, movida por el deseo de contribuir al progreso de toda la humanidad.

Si bien el pensamiento de Kropotkin ejerció gran influencia en la actividad anarquista de Creaghe, es preciso mencionar su adopción respecto al ideario del pedagogo catalán Francisco Ferrer y Guardia, cuyo modelo autodidacta Creaghe intentará aplicar en la Escuela Racionalista de Luján en $1906^{20}$. Esta educación libertaria, basada en la ciencia, implicaba la ausencia de imposiciones ideológicas o partidarias a los alumnos, lo cual provocó hondas polémicas al interior del anarquismo entre quienes pretendían difundir los principios anarquistas a través de las escuelas libertarias y quienes, como Creaghe defendían el modelo integral y laico, abierto a todos los sectores de la sociedad.

\section{Conclusiones}

A lo largo de este trabajo analizamos el modo en que los interlocutores de la polémica fueron consolidando sus respectivas posiciones. Creaghe abandonó por completo su vínculo con el anarquismo individualista, contribuyó a afianzar la tendencia organizadora del anarquismo y participó en el movimiento gremial. Ingenieros, en su acercamiento hacia posiciones reformistas, se desligó de la corriente revolucionaria que había gestado junto a Lugones $y$, luego de desvincularse del Partido Socialista, criticó la posibilidad misma de la revolución y manifestó la necesidad de elaborar reformas concretas dentro de los márgenes del capitalismo.

Si bien tanto Ingenieros como Creaghe propusieron la eliminación del Estado y de todo tipo de poder, y la socialización de los medios de producción, las bases de esa nueva sociedad que buscaron resultaron diferentes. Pese al fundamento natural del orden social garantizado por la sociedad socialista, Ingenieros admitió la necesidad de algún tipo de regulación que permitiese organizar la producción y el consumo y así asegurar la igualdad de condiciones a todos los individuos. Creaghe, en tensión con el individualismo, criticó la posibilidad de un orden espontáneo garantizado por una armonía innata a la naturaleza humana. Frente a esto, sostuvo la posibilidad de

\footnotetext{
${ }^{20}$ Creaghe solventó y dirigió la escuela Racionalista de Luján, inaugurada en 1906 junto a Ernesto Ortiz, un militante anarquista vinculado a la redacción de La Protesta Humana. Creaghe llegó a organizar una colonia de educación agrícola y un internado mixto. El modelo educativo de Ferrer y Guardia, que influyó notablemente en el movimiento pedagógico anarquista latinoamericano, estuvo basado en la coeducación de clases y de sexos, la neutralidad militante, el autodidactismo, el antimemorismo y la confianza en la ciencia. La tendencia educacionista que adoptaba estas ideas, encabezada por Julio Barcos, abrió escuelas racionalistas en diversos puntos de Buenos Aires, y se opuso a la tendencia revolucionaria, encabezada por Gilimón y los doctrinarios puros, cuyo objetivo era educar para la militancia anarquista. Sobre un estudio más profundo en torno al debate educativo del anarquismo véase Suriano (2008) y Puiggrós (1996).
} 
algún tipo de acuerdo entre los individuos que, sin implicar la existencia de una autoridad, pudiese evitar el conflicto entre las libertades individuales.

Pese a que, tanto en el discurso de Ingenieros como en el de Creaghe, la connotación moral de la crítica hacia el capitalismo adquirió un lugar importante, ambos lo hicieron desde concepciones acerca de la moral diferentes. En relación a los elementos libertarios presentes en la obra de Ingenieros concluimos que sus ideas relativas a la destrucción del Estado resultaron próximas a la argumentación de Deville y que la presencia dominante de la crítica moral hacia el capitalismo y la vida social burguesa fue un factor esencial del modernismo literario al que Ingenieros adhirió desde los inicios de su militancia.

El esfuerzo inicial de Ingenieros por lograr la conversión del anarquismo en el socialismo, las diferencias fundamentales que encontramos entre Creaghe e Ingenieros respecto a los supuestos filosófico-políticos de sus respectivas teorías, y el origen plural de los elementos libertarios presentes en las argumentaciones de Ingenieros, nos conducen a rechazar la hipótesis de una posible adscripción ideológica de Ingenieros respecto del anarquismo en su etapa inicial. En efecto, los años inmediatamente posteriores a la publicación de La Montaña encontrarán a Ingenieros polemizando nuevamente con otras figuras del anarquismo como Félix Basterra y Pascual Guaglianone, a través de La Vanguardia y La Protesta Humana. Esta vez, serán no sólo los antagonismos aquello que caracterizará estos debates sino, además, un interés cada vez menor por parte de Ingenieros en la figura misma del anarquista como su interlocutor.

\section{Bibliografía citada}

Revistas:

El Perseguido. Periódico comunista-anárquico, Buenos Aires, 1892-1894.

El Oprimido. Periódico comunista-anárquico. Buenos Aires, 1894-1896.

La Protesta Humana. Periódico anarquista, Buenos Aires, 1897-1900.

Libros y artículos:

Croce, Marcela. La montaña: jacobinismo y orografía. Buenos Aires, Facultad de Filosofía y Letras, Universidad de Buenos Aires, 1995.

Falcón, Ricardo. "Lucha de tendencias en los primeros congresos del Partido Socialista Obrero argentino 1896-1900", Apuntes para la historia del movimiento obrero y antiimperialista latinoamericano, año 1, número 1, 1979.

Los orígenes del movimiento obrero, Buenos Aires, Centro editor de América Latina, 1984. 
"Notas sobre la formación de la Identidad Socialista en Argentina" (avance del libro Los orígenes del Socialismo en Argentina 1830-1900). Rosario: Laborde CIESAL, 2008.

Franzé, Javier. "Lugones, 1897: socialismo y modernismo" en Cuadernos hispanoamericanos, ISSN 0011-250X, № 560, 1997.

Juan Bautista Justo, Madrid, Ediciones de Cultura Hispánica, 1998.

Ingenieros, José (1895): “¿Qué es el socialismo?” en TERÁN, Oscar. José Ingenieros: Pensar la Nación, Buenos Aires, Alianza, 1986.

(1895): "El arte de la sociedad futura". Artículo periodístico, Fondo de archivo ARCEDINCI FA-021 José Ingenieros, ubicación A.1.1.2.

(1896): "Datos inéditos sobre la huelga de los ferrocarrileros y mecánicos". Artículo, Fondo de archivo ARCEDINCI FA-021 José Ingenieros, ubicación A.1.1.3.

y Lugones, Leopoldo (1897). La Montaña. Periódico socialista revolucionario. Buenos Aires, Universidad Nacional de Quilmes, 1998.

Oveed, Iaacov. El anarquismo y el movimiento obrero en Argentina, México, Siglo XXI Editores, 1978.

Poy, Lucas. Los orígenes de la clase obrera en Argentina. Huelgas, sociedades de resistencia y militancia política en Buenos Aires, 1888-1896. Buenos Aires, Imago Mundi, 2014.

Puiggrós, Adriana. Sujetos, disciplina y curriculum en los orígenes del sistema educativo argentino (1885-1916) en Historia de la educación en la Argentina I, Galerna, 1996.

Real de Azúa, Carlos. "Modernismo e ideologías", Punto de vista, $\mathrm{N}{ }^{\circ} 28$, noviembre de 1986.

Suriano, Juan. Anarquistas. Cultura política libertaria en Buenos Aires 1890-1910, Buenos Aires, Manantial, 2008.

Tarcus, Horacio. Marx en Argentina. Sus primeros lectores obreros, intelectuales y científicos, Buenos Aires, Siglo XXI editores, 2007.

, "Espigando la correspondencia de José Ingenieros. Modernismo y Socialismo fin-de-siecle" en Políticas de la Memoria N10/11/12, años 2009/2011, pp. 97-122.

Terán, Oscar. José Ingenieros: Pensar la Nación, Buenos Aires, Alianza, 1986.

Zaragoza Rovira, Gonzalo. Anarquismo argentino (1876-1902), ediciones De la Torre, Buenos Aires, 1996.

Recibido: 7 abril 2015 Aceptado: 2 junio 2015 